\title{
Exploration of ITK with the self help group-a cost effective technique to develop digital databases for sustainable agriculture
}

\author{
Nandadulal Sannigrahi
}

\begin{abstract}
Climate change is inevitable although it is slow but steady. Although this inevitable change is perennial. But the anthropogenic commitment of human civilization in the name of industrialization, urbanization and so called market economy has expedited this change. In the past couple of years, an unprecedented interest and documentation in the phenomenon of climate change and its possible impact in the environment has been noticed. Global temperature is the main indicator of the climate change and a mean increase of average global temperature has a detrimental effect on environment-both on the man-made and natural ecosystem. An increase of spring temperature can accelerate the early flowering of many plants and the melting of ice caps can cause the extinction of valuable flora and fauna in general and marine ecosystem in particular. Thus biodiversity of natural as well as man-made agricultural ecosystem is supposed to be effected leading to the complication of food production. Indian economy, an agricultural based economy will suffer a lot leading to the ever increasing population into a starvation, Not only that the post harvesting management of agricultural crops is too unscientific to maintain a desirable buffer stock for the growing population. Due to climate change, the plants can develop a desirable adaptation much faster than animal but not too fast to cope up with the growing demands of millions. So the convenient tools to be explored with dependable inputs that can catalyze the productivity in sustainable manner for the on growing Population. As far as the modern scientific agricultural information system is concerned, the digital data base comprising of number of desirable parameters can built up to mitigate the problems.

The cost effective agricultural based data base management system with the help of traditional knowledge of farmers including resistant varieties, soil parameters, weather parameters and others expertise opinions to maintain an avenue for the sustainable agricultural for the new millennium. The improved crop varieties along with management system can only solve the problems of emerging crisis corresponding to the global climate change.
\end{abstract}

Key words: Climate change, Market economy, Documentation, Digital Data Base, Sustainable Agriculture, Agriculture information system

\section{Introduction}

Anthropogenic activities knowingly or unknowingly have a tremendous impact on the global climate. The Nations authoritative Intergovernmental Panel on Climate Change (IPCC) has recently once again confirmed the human activity on climate change. The industrialization, globalization along with injudicious implementation of concrete jungles have expedited the emission of green house gases They are reinforcing the earth's natural green house effect and causing the average increase of the mean temperature of the earth. But the main culprits of the green house effect are the oxides of carbon along with methane and oxides of Nitrogen If the rise of the temperature due to human activity is allowed, then by the end of the $21^{\text {st }}$ century, IPCC expects the mother earth's temperature to have risen by between $1^{0} C \& 6^{\circ} C$. The natural water cycle will be disturbed having droughts somewhere while additional rainfall may cause flood like situation. The increase of sea level will may bring catastrophe. The stability of natural environment and sustainability of the economy and human welfare will be affected a lot which may costs $20 \%$ of global income. The irreparable loss of bio-diversity will expedite the gene erosion along with the projections of epidemic like situations will arise both on the human as well as the plant groups that contribute the economic growth. The agricultural practices will suffer a lot and there will be a expansion of starvation of millions in general and third world countries population in particular. So, for the sustainability of the human population with respect to basic socio-economic in general and agricultural crops in particular, the indigenous traditional knowledge and its exploration can mitigate the problem.

\section{Sustainable Development}

The word 'Sustainable' etymologically means i.e. keeps something going over time. The concept of sustainable development first articulated by the world commission of environment and development in 1987 through the well known Brundtland report entitled 'Our common future' reveals about the sharp and demarcating shift in our thinking on the concept of economic development .It was assumed that natural resources are inexhaustible and are available for human welfare. But to-day through the passage of time, it has 
been globally accepted that the sustainable development is such development process that meets 'the needs of present generation without compromising the ability of future generation to meet their own needs'. The definition of above concept expanses a degree of long limitations including the anthromorphic that it does not adequately take equity into account and that is in this form not possible to operational. Wide definition of this concept is highly to be solicited that can grow the sustain development by promising the relieve and elimination of poverty, create equitable standards of living, to satisfy the basic needs of all but not to meet the greed of none and to meet sustainable political practices as a whole. Depending upon the 'Global climate change' issue, the problem of sustainability assumes different meanings. The issues to be resolved - global warming because of green house gas emission, acidification of soil and water, drastic decline of the abiotic components of ecosystem, reckless and injudicious exploitation of natural resources, drastic change in the land use and land cover through the over exploitation of natural resources leading to the desertification of landscapes, associated with the rapid loss of bio-diversity etc-all deserve a whole variety of additional pathways for the development. The meaning of sustainable development also varies with respect to individual and organization. Issues related to the conservation natural resources are to be addressed properly along with the findings of new thought and dimension with respect to guiding principles of sustainability. This guiding principles cut across ecological, economical social and cultural dimension and there are obvious tradeoffs. The following guiding principles can be consulted in course of the adoption of sustainability.

$>$ Conservation of cultural diversity and ecological diversity,

$>$ Constant 'natural capital' and 'sustainable income',

$>$ Anticipatory and precautionary policy approach to resource use, erring on the side of caution,

> Resource use manner that can contribute to equity and social justice while avoiding social disruption,

$>$ Limits of the natural resource within the capacity of the environment to supply renewable resources,

$>$ Qualitative and quantitative development of human well being,

$>$ Pricing of natural values as natural resources to cover full environmental and social costs,

$>$ Global rather than the regional and natural perspective of environmental issues'

$>$ Strong community participation in policy and practice during the process of translation of ecologically sustainable society.

\section{Indigenous Traditional Knowledge (ITK)}

In the context of strong of the strong community participation in policy and practice, the concept of ITK and its exploration is essentially important to address problem and issues of sustainability in the context of climate change.

'When knowledgeable old person dies, whole library disappears' - an African proverb goes. The adjectival word 'indigenous' means "belonging to a place, native' (Oxford English dictionary). The ITK is an integral part of the cultural and history of a local community. It is evolved and refined through many years of regular experiments on the day to day life and the available resources surrounded by the community. According to Ferrington and Martin (1991), ITK can be defined as a basis of knowledge, beliefs and customs which are internally consistent and logical to those holding them and it has much influence upon the people of aboriginal origin than the people of modern substitute. Rather it is a complex set of integrated express of intellectual, empirical, social and special factors that finally shape the human culture. .According to the Gramier (1998), ITK is "unique, traditional, local knowledge existing within and developed around specific condition of women and men indigenous to particular geographical areas". Apparently, the indigenous knowledge very often referred as the knowledge reared by the tribal people as a part of their old age heritage but this knowledge is unauthorized. According to Nakatu (2002) who objected the above misconception and stated that "indigenous People's knowledge can be considered as a subset of what is more broadly referred to as 'Indigenous knowledge'. ITK is not static rather there has been a gradual transmission of knowledge to the adjoining area either on the non-fragmented geographical or even to the fragmented geographical areas by the virtue of the insight of travelers and traders who have dedicate sense of interest-either monetary or sensual as a part of mostly oral tradition. The most recent definition of ITK has been drafted by Gadgil. According to him, "It is a cumulative body of knowledge and beliefs handed down through generation by the cultural transmission about the relationship of the living beings including human with one another and their environment. It is unique to given culture or society". Although the term never to be considered as static and typical but checking door through the innovation occur. So, ITK is a community based functional knowledge system, developed, preserved and refined by the generation of people through the continuous interaction, observation, experimentation with their surrounding of the event. Thus the need of ITK is its usefulness for the sustenance of the community in one hand as well as for the maintenance of genetic resources for continued survival of the community.

Need of the documentation in India; Indigenous communities are represented by nearly 430 district ethnic groups interspersed among 54 millions under 227 linguistic groups and inhabitating different phytogeographical locations. About 75000 species of animals, 340 species of mammals, 1200 kind of birds, 420 
reptiles, 140 amphibians, 2000 species fishes, 50000 insects, 4000 mollusks and other invertebrates are distributed over a landmass of 329 million hectares and coastlines of $7516 \mathrm{kms}$. An appreciable amount proportion of biological components are used by the indigenous communities for value added products and the ethnic groups have been rearing this rich and precious heritage due to their constant and intimate association with the resources. Basically, the knowledge is the result of co-evolutionary relationship between the aboriginal people and the nature since the dawn of the civilization. The following are the main reasons that urge to explore the document of the ITK in the context of global warming and climate change.

3.1 To improve the livelihood of ITK holders and communities:

The ITK holders bear a sound heritage of crop varieties with respect to the edaphic and topographical consequences as this can convey the design of genotypes for sustainable agricultural entrepreneurs in this regard.

\subsection{To accelerate national economy:}

A number of agricultural based industries, pharmaceuticals, cosmetics, bio-pesticides etc. deserve the wide expansion of these markets in order to the existing markets in order to the growing urge of green chemistry and green technology due to their eco-friendly approach. Protecting ITK has a wide degree of potentiality that can expedite the growth rate and GDP of developing countries in general and India in particular.

\subsection{To conserve and restore environment:}

There is a urge of conservation of environment that only can be done by means of the conservation of sustained environment. Traditional knowledge is the most simplest and eco-friendly to materialize the concept.

\subsection{To retard and prevent biopiracy:}

The documentation and authenticity of the ITK is a most novel approach to retard and prevent biopiracy which is invariably essential in the context of the conquering the global market in the name of patent.

\subsection{To combat the climate change for the sustainable development:}

'Traditional Knowledge' \& 'Sustainable development' are contested terms with a degree of varying definitions \& interpretations. Some forms of traditional knowledge are expressed through stories, legends, folklore, rituals, songs and other media. The backbone of Indian economy is pre-dominantly agriculture. On the basis of topography, agro-ecology and their racial and cultural background, the people in general and aboriginal people in particular have adopted diverse agricultural practices with their time-tested indigenous knowledge and technologies and have integrated several related world. The community living in study village possesses knowledge about diverse agricultural know-how related to crop pattern, pest management, soil fertilization, preparation, irrigation practices, harvestation and post-harvestation practices. They acknowledge both the natural and supernatural forces to mould their destiny with respect to economy and endowment Therefore, the gathering of such indigenous knowledge is the decade's call of the 21st century to combat the unforeseen problems in this field due to emerging climate change and the projection of the silver line of $2^{\text {nd }}$ green revolution.

\section{ITK \& Aboriginal people}

The indigenous as well as aboriginal people play a pivotal role in generating knowledge based system of the understanding of environment devising mechanisms to conserve and sustain their natural resources and to establish community based organization that serve as a forum for identifying the issue along with to deal with them through local-level experimentation, innovation, innovation, and exchange of information with other societies (Warch, 1992). Those aboriginal communities have accumulated a store of working knowledge concerning the effects of certain elementary mechanical processes. The apparent movement of and functions of some heavenly bodies, the properties of flora and fauna with respect to their morphology, reproduction potentialities, in context with the different edaphic factors and soil relation. Indigenous knowledge is historically constituted knowledge instrumental in the long term adaptation and human groups to the bio-physical environment (Purecell, 1998).

The backbone of the tribal subsistence based economy is the agriculture. On the basis of topography, agro-ecology and their racial and cultural background, tribes have adopted a diverse agricultural practice with their time-tested indigenous knowledge and technologies and they also have integrated several world view practices. Thus, the knowledge can contribute a little bit to accelerate the pace of the economic progress if the time tested knowledge is justified with the help of scientific tools and technologies that have been emerged after long cultural practices. 


\section{ITK in Sustainable development}

Indigenous knowledge traits can build up the Indigenous knowledge System .Stability, transmission; distribution and practical application are the usual features of TKS It should always be kept in mind that the ITKS is a very sensitive issue related with cultural identity and ethnicity of the stock holders. It reflects the dignity and identity of the local community. But it is a proven and time tested truth that the civilized body has so many things to be learnt from ITKS of nature bound community especially at the time when the blue planet has been suffering severely from so many intangible problems like pollution, loss of biodiversity, war and economic crisis, subsequent food and fuel crisis, genetically modified food controversy, biopiracy in general and global warming in particular.

As far as latest evaluation of UNDP in the context of globalization and market economy is concerned, at least burning and serious problems have been pointed out

1) Challenges of global warming

2) Rapid loss of biodiversity,

3) Growing international inequality,

4) Crisis prone financial market,

5) Emergence of new drug resistance pathogenic strains,

6) Genetic engineering related emerging disputed issues (Grunberg, Kaul, Stern, 1999).

So the urges for sustainable development have been evoked from the core of the mass. "The concept of sustainable has become a common theme in the debates of development has become theme in the debates on development strengthen; even since the famous Brundtland Commission introduced this concept in its celebrated report in the mid 1980 - Brundtland Commission report defined sustainable development as that development which meets the needs of the present without compromising the ability of future generation to meet their own needs" as stated earlier (Panchamukhi,2010).The concept of sustainability into four main categories-environmental, economic, socio-political and cultural stability. According to Panchamukhi, environmental stability has concerned different gradation - week sustainability, Strong sustainability, and Deep ecology. But the deep ecology acknowledges an ecological wisdom by focusing on deep experience, deep questioning and deep commitment. Deep Ecology also acknowledges the spirituality and the supernatural forces that are expressed by the common people, their indigenous knowledge and attributes. Thus this less profitable and the less refined knowledge system is quite helpful for environmental and other sustainability. Thus in the context of hue and cry of climate change, sustainability is the most eco-friendly concept that can show a ray of hope to overcome the stagnation from the future.

\section{Self Help Group (SHG) and Knowledge System Exploration}

The local self government institutes are being promoted as the principal proactive stakeholders in the socio-economic developmental process as the same had been advocated by the required changes in the India's constituent as a result of the 73rd Amendment of Indian constitution. Towards the end of the $11^{\text {th }}$ plan, special emphasis has been given upon the role of civil organization to expedite their socio economic activities through the decentralization of power. In the national context, the national developmental council (NDC) recommended a further amendment to Article $243 \mathrm{G}$ of the constitution to make it mandatory to develop funds, functions and functionaries to panchyats on 11 core areas including 'Poverty alleviation programme' and maintenance of community assets". The stated objective being "to evolve framework for participation and projections of local plans that reflect the needs and aspiration of people so that developmental process becomes a people's movement". Self help groups are being perceived by many as neighborhood substructure who are an integral part of the institute and process of local self governance. These communities use to fulfill their aspirations by ensuring basic services and entitlements rather than purely as civil society institute which can engage representative 'Government' to be responsible, accountable and efficient in delivering manifold services to its actions including self help groups within jurisdiction. Thus, self help groups in India have been deploying to the objective of poverty alleviation, job opportunity increase, acceleration economic growth, promotion of income generation through eco-friendly and sustainable manner.

Even after 66 years of planning through various poverty alleviation programme, the above objective still remains a daydream. The main disadvantageous groups are the women and they constitutes about half of the population of India. According data, 29.8\% and 360 millions Indian were poor in 2009-2010 and in rural areas , the ST exhibits highest level of poverty $\left(47^{\prime} 6 \%\right)$ followed by SC of $(42 \%)$ and $\mathrm{OBC}(31.9 \%)$ against $33.8 \%$ of all classes. In urban areas, SC's have HCR of $34.1 \%$ followed by ST's $30.4 \%$ and OBC $24.3 \%$ against $20.9 \%$ of all classes. $51 \%$ of total workforce of country's is self employed, only $15.5 \%$ are regular wagers or salaried employees and 33.5\% are casual laborers according to the survey by the National Sample Survey Office(NSSO).In India, the overwhelming proportion of workers in the self employment category. About $64 \%$ of the rural and $46 \%$ of the urban work force is engaged in self employment. Microfinance to self help groups 
(SHG) may be considered as a vital tool meeting the women constitute around $50 \%$ of the total human resources in our country.

\section{SHG, Environment management and Sustainable agriculture \& ITK Procurement}

Research and Policy have tended to focus on the relationship between poverty and environmental degradation in terms of pointing out that the poor are both the victims and agents of environmental degradation. They are victims in that they are more likely to live in ecologically vulnerable areas, agents in that they may have no option but complete environmental resources their contributing to the environmental degradation. Vulnerabilities of the ecosystem and its fragility is the most serious concern of this decade of the 21 st century. The anthropogenic activities due to exploitation of the natural resources without any safeguards has granted a no. of problems and the most striking problem is the global climate change problems that has been threatening the conventional life style human beings. The threats of the alteration of ecosystem will bring irreparable changes. The agricultural sector will be the worst affected. The decline of products in terms of 1 st green revolution is a serious problem today due to the stagnation of outcome of high yielding verities. In this context, the urge of attention has been expedited in terms of the indigenous traditional knowledge of agricultural practices with respect of pre-harvesting, harvesting and post-harvesting practices of different type of crops along with crop rotation practices comprising of conventional and non-conventional crops. As the SHG mostly being to the villages and close to the natural ecosystem, they are the stakeholders of such diverse knowledge .Besides these, the knowledge also can be harvested by them as the modes of SHG is basically based on the following -

1) Easy access for community participation,

2) Status of access of amenities,

3) Have greater chance of interaction with the stakeholders of knowledge,

4) Having a high degree of self confidence among the members,

5) Easy penetration to the local government,

6) Close belongings to the nature,

7) Members themselves are the repository of such knowledge essentially solicited in this regard.

Due to the aforesaid advantages experienced by the SHG, they can be used mining of ITK and to formulate a database with respect to agriculture and environmental management in this regard. The following ITK based information harvestation path can be consulted to build up the network and subsequently data base management network can be developed in this regard (see Fig.1).

\section{Need of digital database in ITK-Data procurement}

During the last decade, progress in information technology (IT) is affecting all spheres of our everyday's life staring from education to entertainment. Due to progress in modern well equipped hardware technology, super fast information gathering and huge storage capacities have become possible at affordable cost. Database and data warehousing technologies can be used to store and retrieve huge amount of information that can be computed with internet technology to deliver information in the desired target sink. Such IT based developments provide unique opportunities to improve the utilization and performance of livelihood technologies such as agriculture, education, entertainment and this cost effective system in this regard.

Sustainable development is the urge of this millennium. India's food production improved significantly during the last three decades due to all round efforts in pre-harvesting, harvesting and post-harvesting agricultural operation with modern inputs of different requisites of agricultural operation. However, the Indian agriculture is still facing a lot of problem with respect to productivity. despite significant efforts have been made in the respect of agriculture sector to achieve the target, a lot of embarrassing question have been developed as far as sustainable productivity in general and agriculture in particular. The knowledge dissemination system as par as agricultural system is concerned, the sorts of information is passed through downward filtration system where the attributes obtained from research is conveyed to the farmers as a matter of imposition. Not only that, the traditional system of information dissemination has a lot of drawbacks viz.

Inability of the system to cover all the farmers - as most of the traditional information system does not cover all the target groups due to limitations of both the source and the sink of information.

Lack of avenues to improve performance - the traditional system is one way traffic where the source enforce the sink to carry out, the problem of sink i.e. the farmers are overlooked.

Irrelevance of the delivered information - the traditional system can monitor the general attributes; the problem of individual is highly neglected in this regard.

Under the above circumstances, the sustainability of development in general and agricultural sustainability in particular, the information system is being proposed as follow where the aforesaid problems can be minimized to open an avenue in the field of agricultural information system is concerned for sustainability .SHG can play a pivotal role in this regard to collect the information. 


\subsection{SHG based ITK procurement System for Digital Database Management system}

Sustainability of agriculture system is one of the most important issues of this decade of new millennium. The following network can be the built up a cost effective ITK database management system to facilitate the process to speed up the concept of sustainable agriculture system.

\subsection{Architecture of Database Management system}

The information related to crops, pre-harvesting and post-harvesting practices goes through downward filtration from the upper hierarchical level to the target group. But this practice was the effective tools of $1^{\text {st }}$ green revolution. But the agricultural sustainability deserves the reverse hierarchical information flow to meet up the growing demand. With IT revolution the digital base management system with respect to ecological parameters can be done through the following network.

This database management system comprising the following parts; 1) the stakeholders of ITK, 2) the effective Self Help Group (SHG), 3) The agriculture experts \& Policy makers, 4 4) information users and the target Farmers as the terminal sink.

1) ITK stake holders - The tribal as well as the aboriginal population rear the rich heritage of indigenous knowledge but the knowledge is non-documented and verbal having no proper documentation and transmitted generation after generation verbal mode.

2) Self Help Group - The SHG having wide range as far as their distribution and habitat are concerned, they are very close to the stakeholders. They can easily harvest the precious knowledge by the dint of their accessibility to them. Not only them, they can have the penetration potentiality among the stakeholders as the stakeholders suffer from their usual customs and beliefs not to disclose them.

3) The Agriculture Experts \& the policy makers - The agriculture scientists' along with the other experts can study the collected knowledge and after proper sieving along with the consultation with the policy makers, the framework of the working principle will be done to do so.

4) Users and the Ultimate sink of the harvested knowledge - From the academic as well as professional point of view, the knowledge can be considered to take desirable steps for the growth and sustainability of the harvestation process.

\subsection{Database operation System}

The system of ITK harvestation can be run as par as the following network. The self help group can contact with the stake-holders of ITK via the local body like panchyat (if required). Through proper questionnaire, the information can be explored through door visiting or the mass gathering, the collected information can be sent to the agricultural experts as well as policy makers. After proper sieving of the explored data, the desirable crop can be designed and ultimately sent to the target sink to make the agricultural system sustainable. The data bank can be built up through proper protocol of networking principles. The following working principles can be used to build up effective data base management system to explore ITK with respect to sustainability in the agricultural field. 


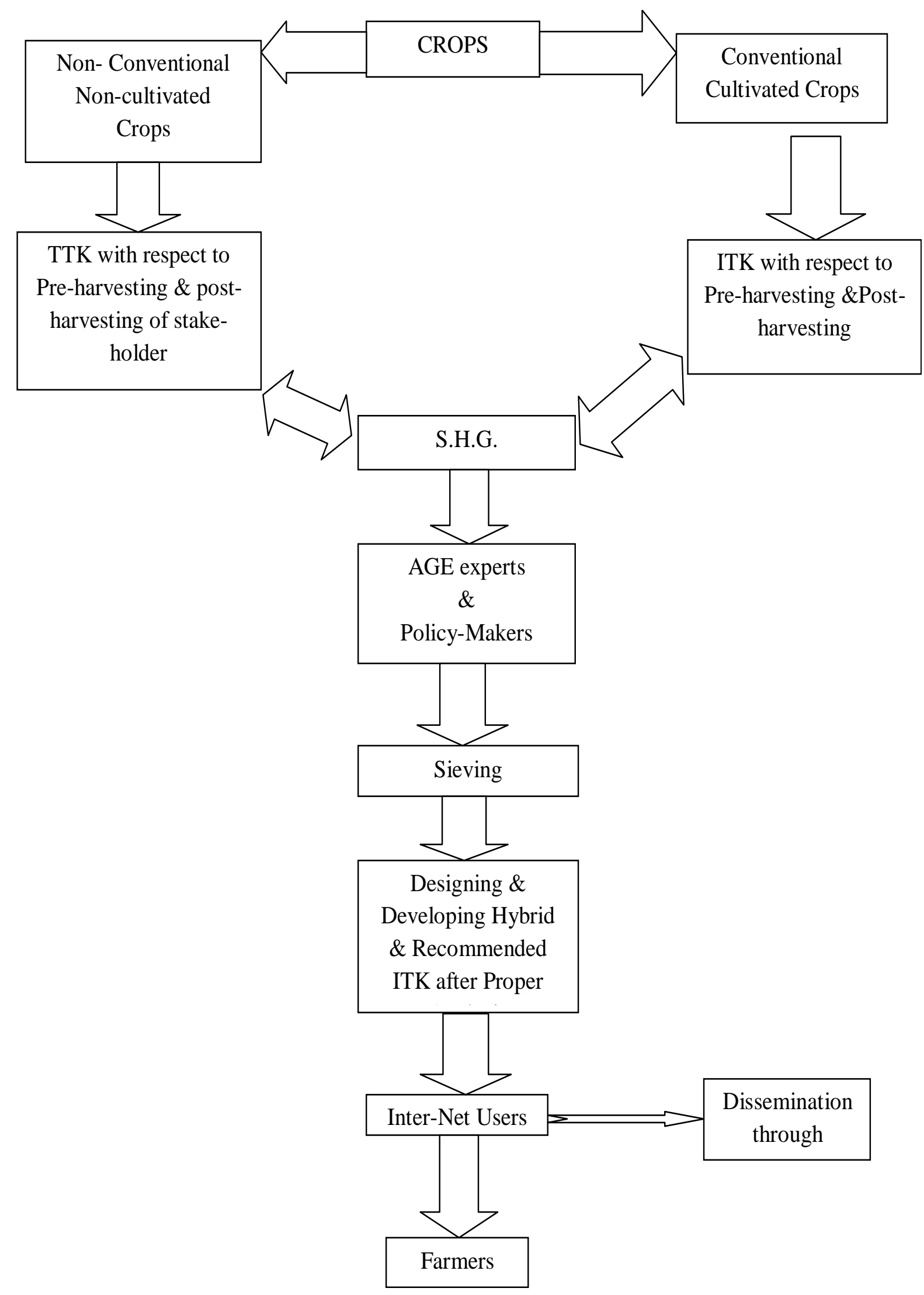

Fig.1 ITK-Exploration \& data-base management system 


\subsection{Effectiveness of ITK database management System}

We can be profound optimistic as far as the benefits to be obtained through this system. The following benefits can be obtained through this system;

1. It will help to explore the very precious non-documented data as far as the agriculture system is concerned.

2. Provide an opportunity to get an idea about non-conventional and non-cultivated crops.

3. To build up the gene bank of the country on the basis of region, climate, topography, altitude, topography etc.

4. To employ the SHG as mean of substitute of alternate employment.

5. To stop the erosion of gene erosion due to globalization.

6. To find the good \& desirable substitute to combat the emerging challenge of climate change.

In a word, it will become effective tool to solve the emerging problems of agricultural scientists and the policy makers to expedite the $2^{\text {nd }}$ green revolution as projected by 2020 .

\section{Conclusion}

Due to globalization accompanied with the industrialization and urbanization, the change of climate is inevitable. The modern science and the technology have not only made the passage of life smooth but also the life span has also been increased. The population of the world has been increasing at very fast rate particularly in the developing and underdeveloped countries. So, to feed the 1200 million people of our country, it is obligatory for the government to render the service. The newly proposed bill of food security of the mass will add another compulsion in this regard. The outcome of the 1st green revolution is likely to be exhausted followed by the stagnation of food production along with number of irreparable damages with respect of global environment - both manmade and natural ecosystem. But there is no room of despair. Every cloud has silver lining. The possible exploration of the traditional crop varieties along with the diversity of crops, soil nutrient facility \& other precautions can act as catalyst in this regard. The stakeholders of all these knowledge are the marginal people of the villages along with the aboriginal people. To mine this precious knowledge from such resources is a herculean task as the people have some own ethics not to disclose them in front of so called civil society. SHG programme can clearly play a central role in the data mining. The programme of SHG has been running to address the poorest of the poor. The members of SHG also suffer from food insecurity with stigmas of sickness. At the individual level, there is evidence that the programme attracts already relatively empowered people and that empowerment occurs among some clients through programme participation. The process of empowerment manifests itself to increase self esteem. They are also play an inevitable role in infrastructure development, markets and technology support, communication level among members, self confidence among self members, and change in the family violence. The frequency of interaction among outsiders, can build social harmony, involvement in community action, sustainable quality and accountability and other manifold activities. SHG will surely bring a change in the social upliftment and also can contribute much in the retrospect in 2nd green revolution in this regard. 'Better late than never'. It is the high time to explore the ITK as a part of agriculture based information disseminations system followed by development of on-line databank to catalyze the food security for all in this blue planet.

\section{References}

[1] ADB 2001 Legal empowerment: Advancing good governance and poverty reduction. Overview report RETA 5856, Manila, Asian Devlopment Bank

[2] Agarwal A.2004, Indigenous and Scientific Knowledge Some critical Comments, IK Monitor 3.

[3] Anonymous, 2005, Quick evaluation of beneficiary oriented(sc/sy) programme of SGRY: Annual report, Ministry of Rural Development, Government of India, Krishi Bhavan, New Delhi.

[4] Asthma. S 1996 Women's health and women's empowerment locality perspective Health and place, 2(1):1-13

[5] Balasubhramanian, A.V. and T.D.Nirmala Devi(2006)-Traditional Knowledge systems of Indian and Srilanka. Centre for Indian Knowledge Systems, Chennai.

[6] Banerjee, S. With D. Basu, D. Biswas and R. Goswami 2006, Indigenous Knowledge Dessimination through Farmer's Network:Exploring Farmer-to_Farmer Communicatiomn, IUAES Inter Congress (Vol-4) New Delhi: IIP.

[7] Chambers, R. With A. Pacey and L.A. Thrupp (eds)1989, Farmers First: Farmer Innovation and Agricultural Research. London: Intermediate Technology Publications.

[8] Dasgupta, A. 2009, The Relevance of 'Indignous Peoples' :A Case Study of the Rajbansi Community of north Bengal, In A Mukherjee with P.K. Pal and R.K.Sen(eds)20109 Environment and Sustainable Devlopment in India, New Delhi: Deep and Deep Publications.

[9] Girach, R. D.(2007)-Methods of Documenting Indigenous Knowledge. The Tradition. Vol. 04. 24-30.

[10] Haverkort, B.(1995)-Agricultural Devlopment with a Focus on Local Resources: ILEIA'S view on Indigenous Knowledge. The Cultural Dimension of Devlopment: Indigenous Knowledge Systems (EDS. D.M.Warren, L.J. Silkkerver and D. Brokensha). Intermediate Technology Publications Ltd., London, 454-457.

[11] Informational Booklet on Intelluctual Poperty and Traditional Knowledge Source: http://www.wipo.int/tk/in/publications/tk_ip.pdf=tkkey 
[12] International Devlopment Research Centre (IDRC)Reports, (April1993)_Article by Daniel A. Morales on knowledge change and the preservation of progress. Vol.21(1), CANADA 4-5

[13] Muchena, O. N. and D. L. Willims, Utilizing Indegenous Knowledge Systems in Agricultural Education to Promote Sustainable Agriculture, Journal Of Agricultural Education, 1991/Winter.

[14] Norgaard, R.B. 1948, Traditional Agricultural Knowledge: Past Performance future prospects and institutional implications, American Journal of Agricultural Economics, 66: 874_878 pp

[15] Silkkerveer, L. J. with G. W. von Liebenstein and D. M. Waren 1993, Networking for Indigenous Knowledge, Indigenous Knowledge and Devlopment Monitor, 1 (1) :2_4pp

[16] Swaminathan.M.S Towards ever-green revolution in farming .In key note addressat International conference on sustainable devlopement and sustainable life cycles.New Delhi.2001

[17] Subba Rao,I.V.Indian agriculture-past laurels and Future challenges in Indian agriculture.27th convention of Indian agriculture Universityies association.9-11 December2002

[18] Waren, D. M. 1991, Using Indigenous Knowledge in Agricultural Devlopment, Paper No. 127, Washington D. C: World Bank 